\title{
IL-1 $\beta$, IL-6 And TNF-Alpha Secretion by PBMNC Stimulated with Polyclonal Antibodies Anti-Hrage (AGE-Like) is Enhanced by Hyperglycemia in Diabetes
}

\section{Caroline Maria Oliveira Volpe, Elisa Duarte Candido, Célio J Castro-Júnior, Paula Martins Ferreira Anjos and José Augusto Nogueira-Machado*}

\author{
Núcleo de Pós-Graduação e Pesquisa (NPGP), Hospital Santa Casa de Belo Horizonte, MG, Brazil
}

*Corresponding author: José Augusto Nogueira-Machado, Núcleo de Pós-Graduação e Pesquisa (NPGP), Hospital Santa Casa de Belo Horizonte, Domingos Vieira 590, Santa Efigênia, 30150-240 Belo Horizonte, MG, Brazil, E-mail: nogueira.machado@pq.cnpq.br, aunog@santacasabh.org.br

\begin{abstract}
Receptor for advanced glycation end products (RAGE) activation is known to play an important role in the development of diabetes complications by amplifying the inflammatory process. Herein, we examined the effect of polyclonal antibodies against human RAGE (Ab anti-hRAGE) on "primed" peripheral blood mononuclear cells (PBMNC by hyperglycemia in type 2 diabetes mellitus (T2DM) patients in comparison to healthy control. ROS generation and IL$1 \beta$, IL- 6 and TNF- $\alpha$ secretion were studied.

PBMNCs were purified utilizing Ficoll-hypaque gradient. ROS was quantified by luminol-dependent chemiluminescence. Antibodies anti- human RAGE (AGE-like) was purched from Sigma Co. The cytokines were from PBMNC culture in presence or in the absence of anti-hRAGE. IL- $1 \beta$, IL- 6 and TNF- $\alpha$ were quantified in the supernatant of $A b$ anti-hRAGE-stimulated PBMNCs trough ELISA.

Ab anti-hRAGE (AGE-like) significantly inhibited ROS production in unstimulated or stimulated PBMNCs from T2DM and healthy controls in a similar way. The percentage of inhibition was greater in primed PBMNC by hyperglycemia in diabetes (T2DM patients). In contrast, anti-hRAGE increased secretion of IL-1 $\beta$, IL- 6 and TNF- $\alpha(p<0.05)$ in the supernatant of Ab anti-hRAGE-stimulated PBMNCs from T2DM patients compared with healthy controls $(p<$ 0.05).

The effect of antibody anti-hRAGE (AGE-like) in primed cells by hyperglycemia in diabetes may activates different signaling network when interact with RAGE on cells surface. Dual results induced by anti-hRAGE (AGE-like) associated with oxidizing response and pro-inflammatory cytokine secretion suggest activation of several signaling network in AGE-RAGE interaction. It may have consequences on innate immunity.
\end{abstract}

\section{Keywords}

Diabetes, RAGE, Antibody anti-human RAGE, ROS, Cytokines, Inflammation

\section{Introduction}

Diabetes mellitus is a immunological disease characterized by metabolic deregulation and inflammation [1]. Hyperglycemia of diabetes is associated with increase in the generation of reactive oxygen species (ROS) and the formation of advanced glycation end products (AGEs) [2-6]. AGEs interact with their respective receptors (RAGEs), a multiligand member of the immunoglobulin superfamily of cell surface molecules, inducing activation of cascade of several signaling pathways associated with diabetes vascular complications [7-10]. In addition to AGEs, RAGE is a receptor for amyloid fibrils, S100/calgranulins and high mobility group box 1 (HMGB-1) protein [11-13]. It is expressed in many types of cells at low levels, such as endothelium, monocytes, macrophages, T-lymphocytes, neuronal cells, and glomerular epithelial cells [14-16]. But, in pathological conditions, RAGE is upregulated after interaction with respective ligands [17]. Activation of RAGE transduces activating signals for: i) NADPH oxidase system; ii) reactive oxygen species (ROS) production; iii) p38 MAPK; iv) extracellular-signal-regulated kinase $1 / 2$; v) Rac; vi) protein kinase C; vii) phosphatidylinositol-3 kinase (PI3K); viii) intracellular calcium $\left(\mathrm{Ca}^{2+}\right)$ mobilization; and ix) I $\mathrm{B}$ kinase- $\beta$ (IKK $\beta)$ in vascular endotheliums, smooth muscle cells and monocytes. These signaling pathways iniciate and sustain the activation NFkappaB target genes leading to the production and secretion of proinflammatory cytokines, chemokines and adhesion molecules, such as IL- $1 \beta$, IL-6, TNF- $\alpha$, E-selectin, vascular endothelial growth factor (VEGF), vascular cell adhesion molecule (VCAM)-1 and intercellular adhesion molecule (ICAM) [18-28]. There are few reports with cells directly associated with innate immunity and it is possible to suggest consequences on signaling of AGE-RAGE interaction induced by hyperglycemia in diabetes. RAGE activation is suggested to be associated with development of diabetes complications by amplifying the inflammatory process [10]. Soluble RAGE (sRAGE) and monoclonal antibodies anti RAGE have used as therapeutic resource for neutralize AGE and to block the interaction AGE-RAGE on cell surface. It has been suggested that hyperglycemia in diabetes may prime cells metabolically inducing altered cellular reactivity [29]. Herein, we examined peripheral blood mononuclear

Citation: Volpe CMO, Candido ED, Castro-Júnior CJ, Anjos PMF, Nogueira-Machado JA (2016) IL-1ß, IL-6 And TNF-Alpha Secretion by PBMNC Stimulated with Polyclonal Antibodies Anti-Hrage (AGE-Like) is Enhanced by Hyperglycemia in Diabetes. Int $\mathrm{J}$ Immunol Immunother 3:020

Received: January 12, 2016: Accepted: June 28, 2016: Published: June 30, 2016 Copyright: @ 2016 Volpe CMO, et al. This is an open-access article distributed under the terms of the Creative Commons Attribution License, which permits unrestricted use, distribution, and reproduction in any medium, provided the original author and source are credited. 
Table 1: Clinical and biochemical characteristics of the studied population.

\begin{tabular}{|c|c|c|c|}
\hline Parameters & T2DM $(n=20)$ & Healthy controls $(n=20)$ & p \\
\hline Female/Male ratio & $14 / 6$ & $12 / 8$ & NA \\
\hline Age (years) & $59.1 \pm 11.4$ & $57.1 \pm 10.0$ & ns \\
\hline Body mass index $\left(\mathrm{kg} / \mathrm{m}^{2}\right)$ & $30.3 \pm 7.6$ & $25.0 \pm 3.6$ & $<0.05$ \\
\hline Disease duration (years) & $4.5 \pm 4.0$ & NA & NA \\
\hline Systolic pressure (mmHg) & $126.0 \pm 11.4$ & $124.4 \pm 12.1$ & ns \\
\hline Diastolic pressure $(\mathrm{mmHg})$ & $85.0 \pm 8.3$ & $81.9 \pm 4.3$ & ns \\
\hline Fasting glucose (mg/dL) & $135.2 \pm 40.4$ & $89.5 \pm 8.5$ & $<0.05$ \\
\hline Glycated hemoglobin (\%) & $8.1 \pm 1.3$ & $5.8 \pm 0.3$ & $<0.05$ \\
\hline Total cholesterol (mg/dL) & $196.8 \pm 43.7$ & $167.7 \pm 29.5$ & $<0.05$ \\
\hline Low density lipoprotein (mg/dL) & $124.0 \pm 37.5$ & $99.2 \pm 25.4$ & $<0.05$ \\
\hline High density lipoprotein (mg/dL) & $45.8 \pm 10.3$ & $55.7 \pm 17.6$ & ns \\
\hline Triglycerides (mg/dL) & $155.9 \pm 45.1$ & $113.2 \pm 40.8$ & $<0.05$ \\
\hline
\end{tabular}

Data as means \pm SD.

NA: not applicable; ns: not significant.

Significant differences between the groups were determined using Student's t-test $(p<0.05)$

cells (PBMNC) primed by hyperglycemia from T2DM patients in comparison to PBMNC from healthy non-diabetic control. We use polyclonal antibodies against human RAGE (Ab anti-hRAGE) as AGE-like. ROS generation and IL- $1 \beta$, IL- 6 and TNF- $\alpha$ secretion in hyperglycemia "primed" PBMNCs from Type 2 diabetes mellitus (T2DM) patients and healthy controls were studied.

\section{Material and Methods}

This study was approved through the Ethical Committee of Santa Casa Hospital (Belo Horizonte - MG, Brazil), and written informed consent was obtained from all participants prior to the commencement of the study.

\section{Subjects}

T2DM patients $(n=20)$, diagnosed according to the criteria of the American Diabetes Association [30], and healthy controls $(\mathrm{n}=20)$, ranging 47-70 years of age, were recruited from the Endocrinology Department of Santa Casa Hospital. Type 2 DM patients were treated with statins and beta-blockers in addition to hypoglycemic drugs. Prior to the study, all volunteers received complete physical examinations, and detailed evaluations of medical histories and laboratory analyses were performed (Table 1). Pregnant women, individuals suffering from alcoholism, infection, inflammation, dementia or malignant diseases and smoking addictions were excluded from this study.

\section{Reagents}

The following reagents were purchased from Sigma-Aldrich (St. Louis, Mo, USA): Rabbit antibody anti-human RAGE (Ab antihRAGE, cat. \#SAB1401326, Lot. 09112), NADPH oxidase inhibitor [diphenyliodonium chloride (DPI); cat. \# 43088] and Phorbol 12,13-dibutyrate (PDB, cat. \# P1269).

\section{Preparation of peripheral blood mononuclear cells (PBMNC)}

PBMNCs were purified from $10.0 \mathrm{~mL}$ of heparinized venous blood, using a Ficoll-Hypaque gradient as previously described [31] with slight modifications. The trypan blue exclusion test showed that the cell viability in all samples was of $>95 \%$.

\section{Determination of reactive oxygen species (ROS)}

Modulations in the generation of ROS were estimated using the luminol quantitative chemiluminescence assay in a Magic Lite luminometer, (Ciba Corning Co., Medfield, MA, USA). The PBMNCs sample was washed in phosphate buffered saline (PBS) and a suspension containing $1 \times 10^{6} \mathrm{PBMNCs} / \mathrm{mL}$ PBS was transferred to an unsealed luminescence tube. Luminol $(200 \mu \mathrm{L})$ dissolved in $0.4 \mathrm{M}$ dimethyl sulphoxide was added to the sample, the final volume of the mixture was adjusted to $500 \mu \mathrm{L}$ with PBS. The chemiluminescence [expressed in relative ligh units $(\mathrm{RLU}) / \mathrm{min}$ ] of each assay mixture was measured for 15 min (basal ROS production), following which addition of the $\mathrm{Ab}$ anti-
hRAGE $(100 \mathrm{ng} / 100 \mu \mathrm{L})$ to the reaction mixture and chemiluminescence measured for $40 \mathrm{~min}$. Finally, NADPH oxidase inhibitor (DPI) $(10 \mu \mathrm{M}$; $100 \mu \mathrm{L}$ ) was added to the reaction mixture and chemiluminescence measured for additional $15 \mathrm{~min}$. The chemiluminescence was also made in the presence of PDB. In this case, basal ROS production was measured for $15 \mathrm{~min}$, following which $20 \mu \mathrm{L}$ of $10^{-4} \mathrm{M}$ PDB was added and ascendant ROS production was determined for $25 \mathrm{~min}$; finally $\mathrm{Ab}$ antihRAGE $(100 \mathrm{ng} / 100 \mu \mathrm{L})$ was added and chemiluminescence recorded for a further $20 \mathrm{~min}$.

\section{Quantification of pro-inflammatory cytokines (IL-1 $\beta$, IL-6 and TNF- $\alpha$ ) in supernatant of PBMNCs}

Aliquots $(100 \mu \mathrm{l})$ of PBMNCs suspension $\left(1 \times 10^{6} / \mathrm{mL}\right)$ from T2DM and healthy controls in Dulbecco's modified Eagle's medium (DMEM), supplemented with $10 \%$ fetal bovine serum (FBS), were incubated in the absence or presence of Ab anti-hRAGE (100 ng/100 $\mu \mathrm{L}$ ) for 72 hours at $37^{\circ} \mathrm{C}$ under $5 \% \mathrm{CO}_{2}$. The final volume was adjusted to $300 \mu \mathrm{L}$ in DMEM supplemented with $10 \% \mathrm{FBS}$. After incubation, the cells were centrifuged and the supernatant collected. The interleukin (IL) 1- $\beta$ (IL-1 $\beta$ human EIA Kit - Enzo Life Sciences, Inc., New York, USA ), IL-6 (IL-6 human EIA Kit - Enzo Life Sciences, Inc., New York, USA) and tumour necrosis factor-alpha (TNF- $\alpha$ human EIA Kit - Enzo Life Sciences, Inc., New York, USA) concentrations were determined through enzyme-linked immunosorbent assay (ELISA).

\section{Statistical Analyses}

The values are presented as the means \pm standard deviation (SD). The nonparametric Kolmogorov-Smirnov test was used to assess the normal distribution of the continuous variables. Comparisons between groups were performed using unpaired Student's t-tests. In some experiments, we also used the chi-square test. All analyses were considered significant at p-values $<0.05$ using Origin 6.0 (Microcal Software Inc., Northampton, MA, USA).

\section{Results}

\section{Suppression of ROS generation in PBMNCs from T2DM and healthy control by either antibody anti-hRAGE or NADPH-oxidase system inhibitior (DPI)}

ROS, expressed as RLU/min, produced by unstimulated PBMNCs from T2DM patients produced higher levels of ROS (186.6 $\pm 39.0)$ compared to healthy controls $(96.6 \pm 11.0)(\mathrm{p}<0.05)$. The use of polyclonal antibodies against human RAGE suppressed ROS generation $29 \%$ and $19 \%$ in cells from T2DM and healthy controls, respectively ( $p>0.05$ by chi-square test). Similar suppression of ROS production was observed in PBMNCs assayed in the presence NADPH oxidase inhibitor (DPI). The percentages of inhibition were $48.0 \%$ for T2DM and $31.0 \%$ for healthy control ( $p>0.05$ ) (Table 2 and Figure 1). PBMNC from patient were more sensitive to inhibition than that from healthy control. 
Table 2: Effect of human RAGE antibody and NADPH oxidase inhibitor diphenyliodonium chloride on reactive oxygen species (ROS) production in human peripheral blood mononuclear cells from T2DM and healthy controls.

\begin{tabular}{|c|c|c|c|c|}
\hline \multirow{2}{*}{ Experiments } & \multicolumn{4}{|c|}{ ROS production (RLU/minutes $\left.\times 10^{-2} \pm S D\right)$} \\
\hline & T2DM & Inhibition (\%) & Healthy controls & Inhibition (\%) \\
\hline 1. $P B M N C s+P B S$ & $186.6 \pm 39.0^{*}$ & & $96.6 \pm 11.0$ & \\
\hline 2. $\mathrm{PBMNCs}+\mathrm{Ab}$ anti-hRAGE & $131.9 \pm 50.0$ & $29^{a}$ & $78.6 \pm 16.8$ & $19^{a}$ \\
\hline 3. PBMNCs $+\mathrm{Ab}$ anti-hRAGE + DPI & $68.0 \pm 32.6$ & $48^{b}$ & $53.9 \pm 10.5$ & $31^{\mathrm{b}}$ \\
\hline
\end{tabular}

$\mathrm{n}=10$ for each group; PBMNCs = peripheral blood mononuclear cells; Ab anti-hRAGE = polyclonal antibodies against human RAGE; DPI = diphenyliodonium chloride (NADPH oxidase inhibitor); RLU = Relative Light Units. ${ }^{p}<0.05$ vs. healthy controls (Student's t-test) Percentage inhibition values were calculated from the expression $[1-\mathrm{R} 2 / \mathrm{R} 1)] \times 100$ :

${ }^{a} \mathrm{R} 1$ and $\mathrm{R} 2$ represent ROS levels in the absence or presence of hRAGEab, respectively

${ }^{\mathrm{b}} \mathrm{R} 1$ and $\mathrm{R} 2$ represent ROS levels in the presence of DPI and hRAGEab, respectively. $\mathrm{P}>0.05$ when similar letters were compared.



Figure 1: Effects of Rabbit antibody anti human RAGE (Ab anti-hRAGE) and NADPH oxidase inhibitor [diphenyliodonium chloride (DPI)] on ROS production by human peripheral blood mononuclear cells (PBMNCs) from Type 2 diabetes patients (T2DM) and healthy controls. Each point represents the average of 10 experiments \pm SD. RLU = Relative Light Units.

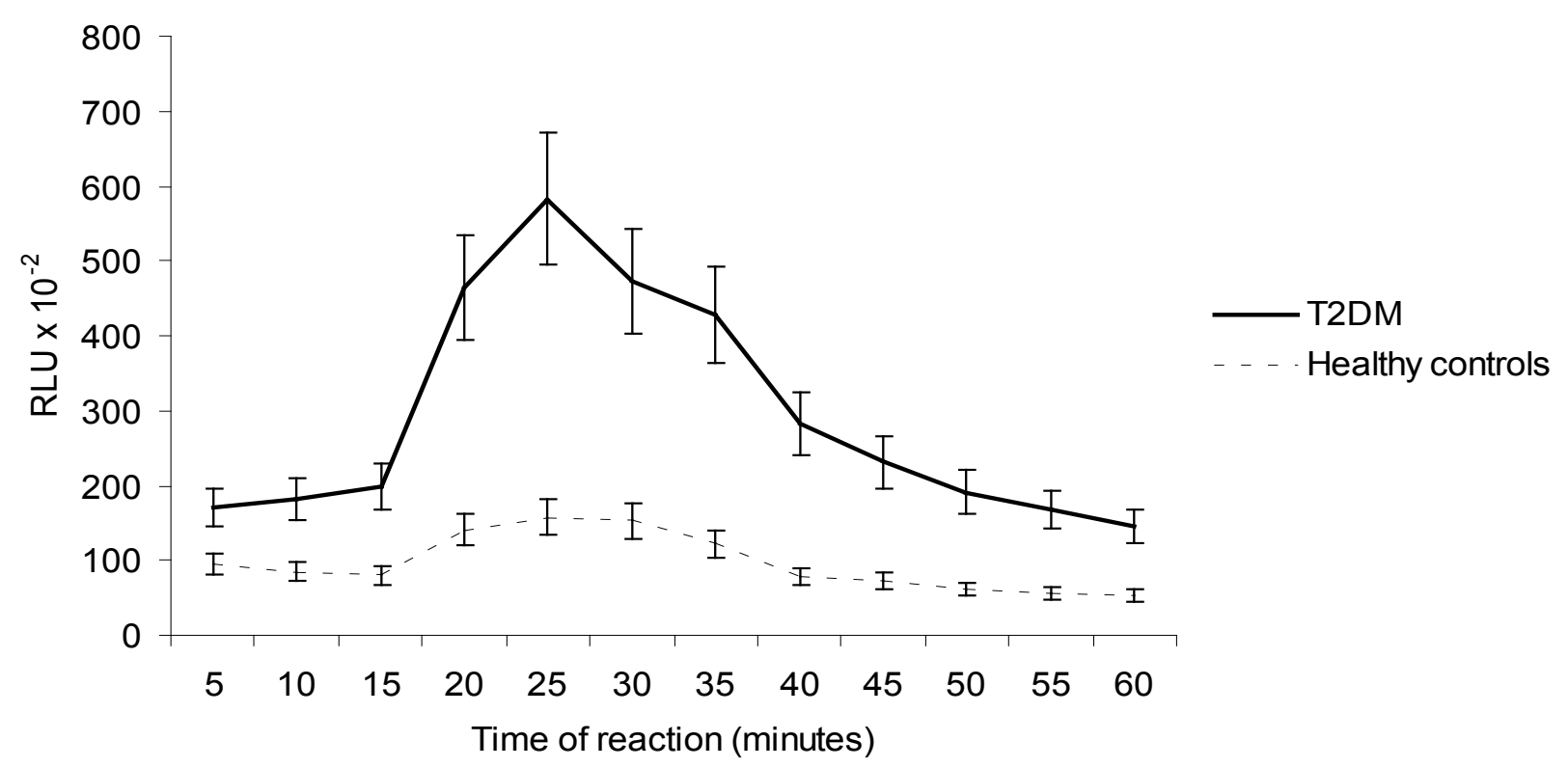

Figure 2: Effects of Rabbit antibody anti-human RAGE (Ab anti-hRAGE) on ROS production in PDB-stimulated human peripheral blood mononuclear cells from T2DM and healthy controls.

Each point represents the average of 3 experiments \pm SD. RLU = Relative Light Units, PDB = phorbol 12,13-dibutyrate ester.

Antibody anti-hRAGE reduced ROS generation in PBMNCs

\section{PDB-stimulated from T2DM and healthy control}

The role of $\mathrm{Ab}$ anti-hRAGE on ROS production by PBMNCs PDB-stimulated is shown in table 2 and figure 2. The phorbol ester activated PBMNCs-ROS derived from T2DM and healthy contols, the results, expressed as percentage of activation, were $166 \%$ and $67 \%$ respectively $(\mathrm{p}<0.05)$. The PBMNCs-ROS derived PDB-stimulated was inhibited by Ab anti-hRAGE. The results expressed as percentage of inhibition were 55\% and 53\% for T2DM and healthy controls, respectively. However, the kinetics studies (Figure 1 and Figure 2) demonstrate that the effect of anti- 

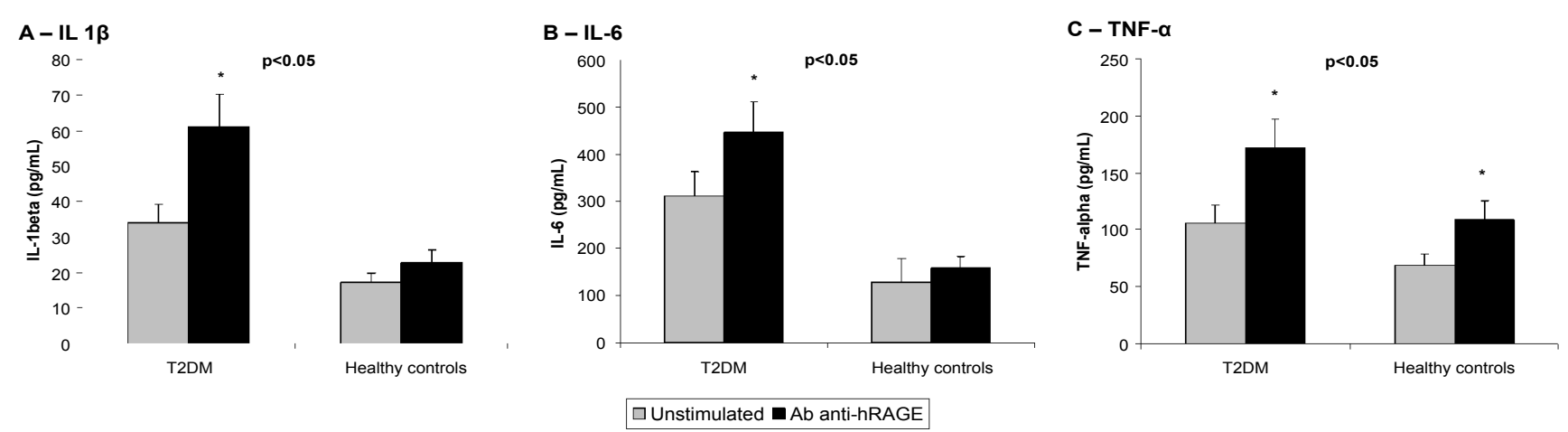

Figure 3: Effects of Rabbit antibody anti human RAGE (Ab anti-hRAGE) on the secretion of IL-1 $\beta$ (A), IL-6 (B) and TNF- $\alpha$ (C) by human peripheral blood mononuclear cells (PBMNCs) from Type 2 diabetes patients (T2DM) and healthy controls. Data as means $(\mathrm{pg} / \mathrm{mL}) \pm \mathrm{SD}$.

$p<0.05$ T2DM vs. healthy controls; ${ }^{*} p<0.05$ vs. unstimulated (Student's t-test).

$n=10$ for each group.

Table 3: Effect of human RAGE antibody on reactive oxygen species (ROS) production in PDB-stimulated human peripheral blood mononuclear cells from T2DM and healthy controls.

\begin{tabular}{|c|c|c|c|c|}
\hline \multirow{2}{*}{ Experiments } & \multicolumn{4}{|c|}{ ROS production (RLU/minutes $\left.\times 10^{-2} \pm S D\right)$} \\
\hline & T2DM & Activation $(\uparrow)^{\mathrm{a}}$ Inhibition $(\downarrow)^{\mathrm{b}}(\%)$ & Healthy controls & Activation $(\uparrow)^{\mathrm{a}}$ Inhibition $(\downarrow)^{\mathrm{b}}(\%)$ \\
\hline 1. $P B M N C+P B S$ & $177.8 \pm 23.2^{*}$ & & $85.8 \pm 8.6$ & \\
\hline 2. $\mathrm{PBMNC}+\mathrm{PDB}$ & $472.4 \pm 44.2$ & $166(\uparrow)$ & $143.3 \pm 10.3$ & $67(\uparrow)$ \\
\hline 3. $P B M N C+P D B+A b$ anti-hRAGE & $210.3 \pm 29.4$ & $55(\downarrow)$ & $67.2 \pm 8.5$ & $53(\downarrow)$ \\
\hline
\end{tabular}

$\mathrm{n}=3$ for each group; PBMNCs = peripheral blood mononuclear cells; PDB = phorbol 12,13-dibutyrate ester; Ab anti-hRAGE = polyclonal antibodies against human RAGE; RLU = Relative Light Units.

aPercentage activation $(\uparrow)$ values were calculated from the expression [(R2/R1 ) - 1] × 100: R1 and R2 represent ROS levels in the absence or presence of PDB, respectively

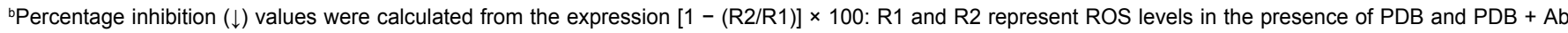
anti-hRAGE, respectively. ${ }^{p} p<0.05$ vs. healthy controls (Student's t-test).

RAGE was more effective in PBMNC from patients, suggesting possible effect of hyperglycemia.

\section{Antibody anti-hRAGE activated proinflammatory cytokines secretion in PBMNCs from T2DM}

As depicted in figure 3, hRAGEab activated the secretion of IL1beta and IL-6 in PBMNCs from T2DM, and stimulated the secretion of TNF-alpha in cells from both studied groups $(\mathrm{p}<0.05)$. The results of the induced effect of hRAGEab in PBMNCs, expressed as mean \pm SD, were: IL-1beta: $61.1 \pm 13.0$ and $22.8 \pm 12.4$; IL-6: $446.1 \pm 71.0$ and $159.0 \pm 59.9$; TNF-alpha: $171.7 \pm 42.0$ and $108.7 \pm 35.7$, for T2DM and healthy controls, respectively. Figure 3 also demonstrated that PBMNCs from T2DM produced significantly $(\mathrm{p}<0.05)$ higher amount of IL-1beta (33.9 \pm 12.4$)$, IL-6 (312.3 \pm 81.2$)$ and TNF-alpha $(105.6 \pm 13.1)$ as compared with cells from healthy control (IL-1beta: $17.2 \pm 5.0$, IL-6: $128.1 \pm 37.2$, TNF-alpha: $68.9 \pm 10.0$ ).

\section{Discussion}

The present study demonstrated that polyclonal antibodies against human RAGE (AGE-like) enhanced cytokines secretion and inhibited ROS generation in PBMNC from type 2 diabetic patients. It has been reported that the pathological consequences of interaction between RAGE with respective ligand leads to the generation of oxidative stress and upregulation of inflammatory pathways [9,3234]. The blockade of RAGE with ligands has been suggested as a possible therapeutic target for controlling inflammatory process. In diabetic animal models, the blockade of RAGE, using soluble RAGE (sRAGE), demonstrated reduction in vascular inflammation and atherosclerotic lesion area and suppression in periodontitisassociated alveolar bone loss [10,35-37]. RAGE deficient animal models showed improvement of nephropathy, suppression of kidney injury and diabetes-accelerated atherosclerosis [38-40]. Moreover, anti-RAGE antibodies increased survival in experimental models of severe sepsis, protected against AGE-mediated podocyte dysfunction and suppressed pro-inflammatory activities of human umbilical venular endothelial cells (HUVECs) induced by HMGB1 [41-44] Thus, theoretically, the use of antibodies anti-RAGE could downregulate inflammatory signaling pathways.
ROS overproduction hyperglycemia-induced result in oxidative stress and it plays a central role in the pathogenesis of diabetes complications [5,6]. Activation of RAGE results in the generation of ROS in dependence of NADPH oxidase [45]. Our results (Table 2 and Table 3) are not in agreements with other authors [18,27,45]. Antibodies anti-hRAGE down-regulated ROS production in PBMNC either from T2DM or from healthy controls (Table 2, Table 3, Figure 1 and Figure 2). It can be due to experimental design we have used. Polyclonal antibodies anti-hRAGE could interact simultaneously with several epitopes on RAGE molecule while monoclonal antibodies or natural AGE interacts with a specific region or epitope. Several metabolic signaling simultaneously activated resulted in different metabolic response. In order to confirm our present results, we performed experiments using an NADPH inhibitor (DPI). The addition of NADPH oxidase inhibitor to PBMNC challenged with antibodies anti-hRAGE showed an addictive effect in reducing ROS production in PBMNC (Table 2 and Figure 1). Both PBMNC from T2DM patients and from healthy controls showed similar and comparable metabolic response in the presence of $\mathrm{Ab}$ anti-hRAGE. However the inhibition in hyperglycemia primed PBMN showed greater when compared to healthy control $(\mathrm{p}<0.05)$ It suggests that the effect of $\mathrm{Ab}$ anti-hRAGE on RAGE can affected by hyperglycemia in diabetes. We studied down regulation of ROS production mediated by anti-hRAGE on PBMNC previously stimulated with a protein Kinase $\mathrm{C}(\mathrm{PKC})$ activator. Our results demonstrated that the activation of ROS production induced by PDB ( phorbol ester) was greater in PBMNMC from patients and was fully reversed by $\mathrm{Ab}$ anti-hRAGE in cells from T2DM and healthy controls in similar percentage of inhibition (55 and $53 \%$, respectively) (Table 3 and Figure 2). It may suggests that the effect of antibodies anti-hRAGE (AGE-like) depends on PKC and /or NADPH-oxidase signaling pathways. Our present data demonstrated that polyclonal antibody anti-hRAGE induced ROS (oxidizing response) inhibition and increased cytokine secretion by PBMNC from T2DM. It suggests a dual effect for antibodies anti-hRAGE (AGE-like). Inflammatory changes observed in the presence of hyperglycemia have been associated with NF-kappaB activation [46,47]. It is also described that RAGE activation leads to sustained and chronic activation of 
NF-kappaB [32-34]. Surprisingly, our results showed that antibodies anti-hRAGE (AGE-like) increased secretion of pro-inflammatory cytokines (IL-1 $\beta$, IL- 6 and TNF- $\alpha$ ) in cultured PBMNCs from T2DM, but inhibited ROS generation. Secretion of TNF-alpha was stimulated in cells from both studied groups (Figure 3 ). The increase of IL- $1 \beta$ may suggest the involvement of inflammasome in diabetic complications. It has been reported that increased levels of TNF, IL-1 $\beta$ and expression of NRLP3-inflammasome are associated with endothelial dysfunction and progression of atherosclerosis [48-50]. Ruscitti et al. [50] demonstrated that patients with diabetes and Rheumatoid Arthritis (T2D/RA) increase IL- $\beta$ when compared with other groups. Antibodies anti-RAGE has no effect on periodontitis, but down-modulated renal complication in diabetic rats and improves neovascularization in the ischemic leg treatment in diabetic mice [5052]. The use of antibodies anti-RAGE leads to a controversial results and needs further studies.

Our results suggests that antibodies anti-hRAGE act as AGE-like ligand potentiating the inflammatory response activating different signaling pathways associated to cytokine secretion in cells from patients in comparison to that from healthy control.

It suggests a very complicated phenomenon with mechanism still not fully known. Thus, the use of experimental and therapeutic antibodies, such as, mono or polyclonal antibodies anti-RAGE, need to be used carefully and reinforce the suggestion that the role of AGERAGE in pathogenesis of diabetic complications is more complex than it seems.

In conclusion, the effect of antibody anti-hRAGE (AGE-like) in primed cells by hyperglycemia in diabetes may activates different signaling network when interact with RAGE on cells surface leading to a dual results associated with oxidizing response and pro-inflammatory cytokine secretion. It may have consequences on innate immunity.

\section{Conflicts of Interest}

The authors confirm that there are no conflicts of interest.

\section{Acknowledgments}

The authors would like to thank FAPEMIG, CNPq, CAPES and Rede Mineira de Toxina Terapêutica 26/12.

\section{References}

1. Pickup JC (2004) Inflammation and activated innate immunity in the pathogenesis of type 2 diabetes. Diabetes Care 27: 813-823.

2. Schmidt AM, Vianna M, Gerlach M, Brett J, Ryan J, et al. (1992) Isolation and characterization of two binding proteins for advanced glycosylation end products from bovine lung which are present on the endothelial cell surface. J Biol Chem 267: 14987-14997.

3. Neeper M, Schmidt AM, Brett J, Yan SD, Wang F, et al. (1992) Cloning and expression of a cell surface receptor for advanced glycosylation end products of proteins. J Biol Chem 267: 14998-15004.

4. Brownlee M, Cerami A, Vlassara H (1988) Advanced glycosylation end products in tissue and the biochemical basis of diabetic complications. $\mathrm{N}$ Engl J Med 318: 1315-1321.

5. Ceriello A (2003) New insights on oxidative stress and diabetic complications may lead to a "causal" antioxidant therapy. Diabetes Care 26: 1589-1596.

6. Giugliano D, Ceriello A, Paolisso G (1996) Oxidative stress and diabetic vascular complications. Diabetes Care 19: 257-267.

7. Bu DX, Rai V, Shen X, Rosario R, Lu Y, et al. (2010) Activation of the ROCK1 branch of the transforming growth factor-beta pathway contributes to RAGEdependent acceleration of atherosclerosis in diabetic ApoE-null mice. Circ Res 106: 1040-1051.

8. Tan KC, Chow WS, Ai VH, Metz C, Bucala R, et al. (2002) Advanced glycation end products and endothelial dysfunction in type 2 diabetes. Diabetes Care 25: $1055-1059$

9. Basta G, AM Schmidt, R De Caterina (2004) Advanced glycation end products and vascular inflammation: implications for accelerated atherosclerosis in diabetes. Cardiovasc Res 63: 582-592.

10. Bucciarelli LG, Wendt T, Rong L, Lalla E, Hofmann MA, et al. (2002) RAGE is a multiligand receptor of the immunoglobulin superfamily: implications for homeostasis and chronic disease. Cell Mol Life Sci 59: 1117-1128.
11. Schmidt AM, Yan SD, Yan SF, Stern DM (2001) The multiligand receptor RAGE as a progression factor amplifying immune and inflammatory responses. J Clin Invest 108: 949-955.

12. Stern D, Yan SD, Yan SF, Schmidt AM (2002) Receptor for advanced glycation endproducts: a multiligand receptor magnifying cell stress in diverse pathologic settings. Adv Drug Deliv Rev 54: 1615-1625.

13. Ramasamy R, Yan SF, Herold K, Clynes R, Schmidt AM (2008) Receptor for advanced glycation end products: fundamental roles in the inflammatory response: winding the way to the pathogenesis of endothelial dysfunction and atherosclerosis. Ann N Y Acad Sci 1126: 7-13.

14. Brett J, Schmidt AM, Yan SD, Zou YS, Weidman E, et al. (1993) Survey of the distribution of a newly characterized receptor for advanced glycation end products in tissues. Am J Pathol 143: 1699-1712.

15. Wendt TM, Tanji N, Guo J, Kislinger TR, Qu W, et al. (2003) RAGE drives the development of glomerulosclerosis and implicates podocyte activation in the pathogenesis of diabetic nephropathy. Am J Pathol 162: 1123-1137.

16. Rong LL, Yan SF, Wendt T, Hans D, Pachydaki S, et al. (2004) RAGE modulates peripheral nerve regeneration via recruitment of both inflammatory and axonal outgrowth pathways. FASEB J 18: 1818-1825

17. Sparvero LJ, Asafu-Adjei D, Kang R, Tang D, Amin N, et al. (2009) RAGE (Receptor for Advanced Glycation Endproducts), RAGE ligands, and their role in cancer and inflammation. J Transl Med 7: 17.

18. Yan SD, Schmidt AM, Anderson GM, Zhang J, Brett J, et al. (1994) Enhanced cellular oxidant stress by the interaction of advanced glycation end products with their receptors/binding proteins. J Biol Chem 269: 9889-9897.

19. Schiekofer S, Andrassy M, Chen J, Rudofsky G, Schneider J, et al. (2003) Acute hyperglycemia causes intracellular formation of $\mathrm{CML}$ and activation of ras, p42/44 MAPK, and nuclear factor kappaB in PBMCs. Diabetes 52: 621-633.

20. Taguchi A, Blood DC, del Toro G, Canet A, Lee DC, et al. (2000) Blockade of RAGE-amphoterin signalling suppresses tumour growth and metastases. Nature 405: 354-360

21. You J, Peng W, Lin X, Huang QL, Lin JY (2010) PLC/CAMK IV-NF-kappaB involved in the receptor for advanced glycation end products mediated signaling pathway in human endothelial cells. Mol Cell Endocrinol 320: 111117.

22. Creager MA, Lüscher TF, Cosentino F, Beckman JA (2003) Diabetes and vascular disease: pathophysiology, clinical consequences, and medical therapy: Part I. Circulation 108: 1527-1532

23. Bierhaus A, Hofmann MA, Ziegler R, Nawroth PP (1998) AGEs and their interaction with AGE-receptors in vascular disease and diabetes mellitus. I. The AGE concept. Cardiovasc Res 37: 586-600.

24. Kilhovd BK, Berg TJ, Birkeland KI, Thorsby P, Hanssen KF (1999) Serum levels of advanced glycation end products are increased in patients with type 2 diabetes and coronary heart disease. Diabetes Care 22: 1543-1548.

25. Kislinger T, Fu C, Huber B, Qu W, Taguchi A, et al. (1999) N(epsilon)(carboxymethyl)lysine adducts of proteins are ligands for receptor for advanced glycation end products that activate cell signaling pathways and modulate gene expression. J Biol Chem 274: 31740-31749.

26. Tan KC, Chow WS, Tam S, Bucala R, Betteridge J (2004) Association between acute-phase reactants and advanced glycation end products in type 2 diabetes. Diabetes Care 27: 223-228.

27. Thallas-Bonke V, Thorpe SR, Coughlan MT, Fukami K, Yap FY, et al. (2008) Inhibition of NADPH oxidase prevents advanced glycation end productmediated damage in diabetic nephropathy through a protein kinase $\mathrm{C}$-alphadependent pathway. Diabetes 57: 460-469

28. Xu D, Kyriakis JM (2003) Kyriakis, Phosphatidylinositol 3'-kinase-dependent activation of renal mesangial cell Ki-Ras and ERK by advanced glycation end products. J Biol Chem 278: 39349-39355.

29. Fagundes-Netto FS, Anjos PM, Volpe CM, Nogueira-Machado JA (2013) The production of reactive oxygen species in TLR-stimulated granulocytes is not enhanced by hyperglycemia in diabetes. Int Immunopharmacol 17: 924-929.

30. American Diabetes Association (2010) Diagnosis and classification of diabetes mellitus. Diabetes Care 1: S62-69.

31. Bicalho HM, Gontijo CM, Nogueira-Machado JA (1981) A simple technique for simultaneous human leukocytes separation. J Immunol Methods 40: 115116.

32. Bierhaus A, Nawroth PP (2009) Multiple levels of regulation determine the role of the receptor for AGE (RAGE) as common soil in inflammation, immune responses and diabetes mellitus and its complications. Diabetologia 52: 2251-2263.

33. Bierhaus A, Schiekofer S, Schwaninger M, Andrassy M, Humpert PM, et al. (2001) Diabetes-associated sustained activation of the transcription factor nuclear factor-kappaB. Diabetes 50: 2792-2808. 
34. Bierhaus A, Stern DM, Nawroth PP (2006) RAGE in inflammation: a new therapeutic target? Curr Opin Investig Drugs 7: 985-991.

35. Park L, Raman KG, Lee KJ, Lu Y, Ferran LJ Jr, et al. (1998) Suppression of accelerated diabetic atherosclerosis by the soluble receptor for advanced glycation endproducts. Nat Med 4: 1025-1031

36. Sakaguchi T, Yan SF, Yan SD, Belov D, Rong LL, et al. (2003) Central role of RAGE-dependent neointimal expansion in arterial restenosis. J Clin Invest 111: 959-972.

37. Harja E, Bu DX, Hudson BI, Chang JS, Shen X, et al. (2008) Vascular and inflammatory stresses mediate atherosclerosis via RAGE and its ligands in apoE-/- mice. J Clin Invest 118: 183-194.

38. Myint KM, Yamamoto Y, Doi T, Kato I, Harashima A, et al. (2006) RAGE control of diabetic nephropathy in a mouse model: effects of RAGE gene disruption and administration of low-molecular weight heparin. Diabetes 55 2510-2522.

39. Yonekura H, Yamamoto Y, Sakurai S, Watanabe T, Yamamoto H (2005) Roles of the receptor for advanced glycation endproducts in diabetes-induced vascular injury. J Pharmacol Sci 97: 305-311.

40. Soro-Paavonen A, Watson AM, Li J, Paavonen K, Koitka A, et al. (2008) Receptor for advanced glycation end products (RAGE) deficiency attenuates the development of atherosclerosis in diabetes. Diabetes 57: 2461-2469.

41. Müller-Krebs S, Kinm LP, Madhusudhan T, Isermann B, Reiser J, et al. (2012) Human RAGE antibody protects against AGE-mediated podocyte dysfunction. Nephrol Dial Transplant 27: 3129-3136.

42. Lutterloh EC, Opal SM, Pittman DD, Keith JC Jr, Tan XY, et al. (2007) Inhibition of the RAGE products increases survival in experimental models of severe sepsis and systemic infection. Crit Care 11: R122.

43. Treutiger CJ, Mullins GE, Johansson AS, Rouhiainen A, Rauvala HM et al. (2003) High mobility group 1 B-box mediates activation of human endothelium. J Intern Med 254: 375-385.
44. Luo Y, Li SJ, Yang J, Qiu YZ, Chen FP (2013) HMGB1 induces an inflammatory response in endothelial cells via the RAGE-dependent endoplasmic reticulum stress pathway. Biochem Biophys Res Commun 438: 732-738.

45. Yan SF, Ramasamy R, Naka Y, Schmidt AM (2003) Glycation, inflammation, and RAGE: a scaffold for the macrovascular complications of diabetes and beyond. Circ Res 93: 1159-1169.

46. Pieper GM, Riaz-ul-Haq (1997) Activation of nuclear factor-kappaB in cultured endothelial cells by increased glucose concentration: prevention by calphostin C. J Cardiovasc Pharmacol 30: 528-532.

47. Yerneni KK, Bai W, Khan BV, Medford RM, Natarajan R (1999) Hyperglycemiainduced activation of nuclear transcription factor kappaB in vascular smooth muscle cells. Diabetes 48: 855-864.

48. Susana Vallejo, Erika Palacios, Tania Romacho, Laura Villalobos, Concepción Peiró, et al. (2014) The interleukin-1 receptor antagonist anakinra improves endothelial dysfunction in streptozotocin-induced diabetic rats. Cardiovasc Diabetol 13: 158

49. Isoda K, Akita K, Isobe S, Niida T, Adachi T, et al. (2014) Interleukin-1 recepto antagonist originating from bone marrow-derived cells and non-bone marrowderived cells helps to suppress arterial inflammation and reduce neointimal formation after injury. J Atheroscler Thromb 21: 1208-1218.

50. Ruscitti P, Cipriani P, Di Benedetto P, Liakouli V, Berardicurti O, et al. (2015) Monocytes from patients with rheumatoid arthritis and type 2 diabetes mellitus display an increased production of interleukin (IL)-1ß via the nucleotidebinding domain and leucine-rich repeat containing family pyrin 3(NLRP3)inflammasome activation: a possible implication for therapeutic decision in these patients. Clin Exp Immunol 182: 35-44.

51. Grauballe MB, Østergaard JA, Schou S, et al. (2016) Blockade of RAGE in Zucker obese rats with experimental periodontitis. J Periodontal Res.

52. Tekabe Y, Anthony T, Li Q, Ray R, Rai V, et al. (2015) Treatment effect with anti-RAGE $F(a b ') 2$ antibody improves hind limb angiogenesis and blood flow in Type 1 diabetic mice with left femoral artery ligation. Vasc Med 20: 212 218. 